Article

\title{
Secondary Metabolites in Ramalina terebrata Detected by UHPLC/ESI/MS/MS and Identification of Parietin as Tau Protein Inhibitor
}

\author{
Alberto Cornejo ${ }^{1, *}$, Francisco Salgado ${ }^{2}$, Julio Caballero ${ }^{3}$, Reinaldo Vargas ${ }^{4}$, Mario Simirgiotis 5 \\ and Carlos Areche ${ }^{2, *}$ \\ 1 Facultad de Medicina, Escuela de Tecnología Médica, Universidad Andrés Bello, Sazié 2315, Primer Piso, \\ Santiago 8370092, Chile \\ 2 Departamento de Química, Facultad de Ciencias, Universidad de Chile, Ñuñoa, Santiago 8320000, Chile; \\ fsalgado@ug.uchile.cl \\ 3 Centro de Bioinformática y Simulación Molecular, Facultad de Ingeniería, Universidad de Talca, 2 Norte 685, \\ Casilla 721, Talca 3460000, Chile; jcaballero@utalca.cl \\ 4 Departamento de Biología, Universidad Metropolitana de Ciencias de la Educación, \\ Avda. Jose Pedro Alessandri 774, Nuñoa, Santiago 8320000, Chile; reinaldo.vargas@umce.cl \\ 5 Laboratorio de Productos Naturales, Instituto de Farmacia, Facultad de Ciencias, \\ Universidad Austral de Chile, Casilla 567, Valdivia 5090000, Chile; mario.simirgiotis@gmail.com \\ * Correspondence: alberto.cornejo@unab.cl (A.C.); areche@uchile.cl (C.A.); \\ Tel.: +56-2-2770-3610 (A.C.); +56-2-2978-7259 (C.A.)
}

Academic Editors: Ana Maria Gomez Caravaca and David Arraez-Roman Received: 24 June 2016; Accepted: 1 August 2016; Published: 18 August 2016

\begin{abstract}
Liquid chromatography coupled with mass spectrometry is an outstanding methodology for fast analysis of phenolic compounds in biological samples. Twenty two compounds were quickly and accurately identified in the methanolic extract of the Antarctic lichen Ramalina terebrata for the first time using ultra high pressure liquid chromatography coupled with photodiode array detector and high resolution mass spectrometry (UHPLC-PDA-Q/Orbitrap/MS/MS). In addition, the extract and the four compounds isolated from this species were tested for the inhibitory activity of tau protein aggregation, which is a protein involved in Alzheimer's disease (AD). All compounds showed null activity with the exception of parietin, which it was able to inhibit aggregation process of tau in a concentration range between $3 \mu \mathrm{g} / \mathrm{mL}(10 \mu \mathrm{M})$ to $28 \mu \mathrm{g} / \mathrm{mL}(100 \mu \mathrm{M})$. In addition, we show how parietin interact with tau ${ }^{306} \mathrm{VQIVYK}^{311}$ hexapeptide inside of the microtubule binding domain (4R) with the help of molecular docking experiments. Finally, the constituents present in the methanolic extract could possibly contribute to the established anti-aggregation activity for this extract and this in-depth analysis of the chemical composition of $R$. terebrata could guide further research into its medicinal properties and potential uses.
\end{abstract}

Keywords: Alzheimer's disease; docking; Ramalina; tau protein; lichens; parietin; UHPLC/MS

\section{Introduction}

Lichens are symbiotic associations between heterotrophic fungi and algae and/or cyanobacteria. A peculiarity of lichen is its remarkable ability to tolerate extreme atmospheric conditions such as low temperatures in polar zones including the Arctic and Antarctic regions; these regions are very cold; the coldest temperature ever known on earth $\left(-129^{\circ} \mathrm{F}\right)$ was recorded in Antarctica. These environmental conditions are responsible for the diversity of secondary metabolites produced in lichens [1-5]. Lichen substances are mainly synthesized via poly-malonyl, shikimate, and mevalonic acid pathway, which have afforded several interesting and unique phenolic structures such as dibenzofurans, depsides, depsidones, depsones, quinones and pulvinic acid derivatives [1-7]. 
Alzheimer's disease is the most common form of dementia. There are two main proteins involved, $\beta$-amyloid protein and microtubule-associated tau protein. Both proteins are characterized by the deposition of plaques and neurofibrillary tangles, respectively [8]. Physiologically, tau protein is involved in axonal transport and microtubule stability. However, once tau is hyper-phosphorylated, it detached from microtubules and starts to form aggregates in soma and dendrites of neuron cells [9]. Tau is an unfolded protein whose structure has two fibril-forming motif, ${ }^{275} \mathrm{VQIINK}^{280}$ and ${ }^{306}$ VQIVYK ${ }^{311}$ [10]. Besides, in order to form the fibrillar structure of tau, is required the addition of polyanions such as heparin which suggest an important role of electrostatic interaction to form both fibrils and aggregates [11]. These two motifs are within the microtubule binding domain of tau and are prone to forming a cross $\beta$ structure [12,13].

The determination of amyloid-like structure reveals the presence of moieties involved in $\beta$ sheets pair formation [14], this "steric zipper" is formed from short self-complementary segments of the amyloid [15]. Thus, this formation is a central part of proto-filaments, whereas the rest of the protein remains unfolded outside of the main axis [16]. The Q-exactive focus is a newly released hybrid high resolution mass spectrometer used for metabolomics analysis including pesticides, herbicides, drugs, antibiotics, small peptides and several other organic molecules [17-21]. The hyphenated Q-exactive focus instrument combines ultra high pressure liquid chromatography coupled with photodiode array detector (UHPLC-PDA) with an orbital trap and a high-resolution collision cell, which allows high resolution $\mathrm{MS}^{\mathrm{n}}$ fragments [17-21].

On the other hand, molecular docking is a computational method used for the prediction of ligand-receptor interactions and is an important tool for rational drug design [22]. Today, molecular docking is the most important theoretical method to determine the orientation of the ligands inside a binding site. Particularly, the challenges of molecular docking are the following: the prediction of ligands proper orientation, the prediction of the binding energies and the prediction of novel, effective drugs by using the structural knowledge obtained from the models [22-24]. Several examples using these computational methods have been already reported [23-28].

The present work describes the UHPLC chromatographic fingerprints plus the isolation of the main secondary metabolites together with the tau aggregation inhibitory activity of methanolic extract of Ramalina terebrata. Hook. and Taylor. Based on the reported activity of fulvic acid [29] we decided to investigate parietin, in order to demonstrate its capacity to inhibit tau protein aggregation. Moreover, we modeled the structure of the complex between parietin and fibril-forming motif VQIVYK of tau using docking experiments. Hence, we are able to demonstrate that parietin is able to create hydrogen bonds (HB) with lysine residues.

\section{Results and Discussion}

From the methanolic extract, the following compounds were isolated: parietin 1, usnic acid 2, atraric acid 3 and inositol 4 (Figure 1) using a combination of chromatographic techniques [30].<smiles>COC(=O)c1c(C)cc(O)c(C)c1O</smiles>

Figure 1. Structures of compounds 1-4 isolated from Antartic lichen R. terebrata. 
Initially, the methanolic extract was screened by Thioflavin $\mathrm{T}$ (ThT) at concentration ranging from 100 to $1000 \mu \mathrm{g} / \mathrm{mL}$ and the results reveled that at $1000 \mu \mathrm{g} / \mathrm{mL}$ the inhibitory activity against aggregation process of tau protein was almost complete (Figure 2). Therefore, we have performed the isolation of lichen substances from this extract for further testing of this activity. All isolated compounds were tested in ThT fluorescence assay, since it has been demonstrated that ThT is able to bind to fibrils from both synthetic and biological sources [31,32]. None of these compounds were active to prevent tau aggregation with the exception of parietin (Figure 2).
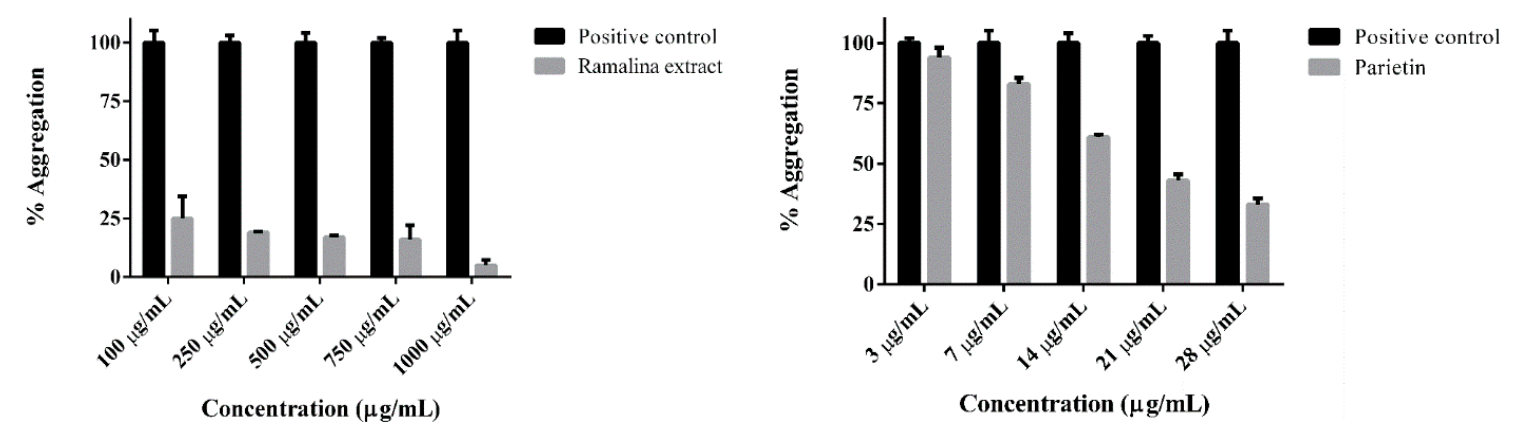

Figure 2. Tau aggregation process inhibited by both Ramalina extract and parietin. Black and grey bars represent positive control (aggregation) and inhibition respectively. A paired samples-t-test was conducted in order to compare control (aggregation) and tau inhibitors (Ramalina extract and parietin). There was a significant difference for both Ramalina extract $t(4)=25, p<0.05$ and parietin $t(4)=3.223$, $p<0.05$ (data are represented as Mean \pm SEM).

Parietin, an orange anthraquinone pigment, is a metabolite very common in the family Teloschistaceae. Several biological activities for this compound have been summarized [1,4]. Besides, it is noteworthy to mention that parietin isolated from Xanthoria parietina (Linnaeus) Theodor Fries showed antibacterial activity against $S$. aureus (ATCC and clinical isolate strains), antifungal activity towards Rhizoctonia solani, Botrytis cinerea and Candida albicans. In contrast, parietin did not show any effect regarding anticancer and antiproliferative activity [2-4]. Gauslaa and Ustvedt reported that parietin may reduce the effect of UV radiations [2-4]. However, there is no information regarding its capacity to inhibit tau aggregation process. Furthermore, according to our knowledge, there is no published data on anti-aggregation properties of lichen compounds.

The aggregation assay was performed using fragment $4 \mathrm{R}$ of the protein tau as positive control. Once we tested parietin by ThT, our results showed that parietin was able to inhibit aggregation process of tau in a concentration range between $3 \mu \mathrm{g} / \mathrm{mL}(10 \mu \mathrm{M})$ to $28 \mu \mathrm{g} / \mathrm{mL}(100 \mu \mathrm{M})$ (Figure 2) showing a dose-response effect. The inhibitory effect of parietin at $28 \mu \mathrm{g} / \mathrm{mL}$ was by $75 \%$.

Some compounds have been described for their anti-aggregating effect against over either amyloid- $\beta$ or tau protein [33-35]. In addition, anthraquinones compounds such as daunorubicin, adriamycin and emodin inhibit tau aggregation and also diminish paired helical filaments in cells [36]. A previous report has shown that emodin, an anthraquinone related to parietin has profound effects on aggregation process of tau protein [36], this difference could be because parietin has a methoxy group at C-3 position instead of hydroxyl group of emodin.

There are previous evidences that negatively charged molecules such as orange-G bind specifically to the lysine residues of tau fibril-forming motifs VQIVYK [37]. Considering that parietin has groups with a negative charge density, we proposed that its activity against aggregation process of tau is due to molecular interactions with fibril-forming motifs. In the complex between orange-G and VQIVYK, the fragment of tau has a $\beta$-sheet form with the dye binding between two sheets. Considering this information, we constructed the possible tridimensional structure of parietin in interaction with the tau VQIVYK motif using docking. Since we do not have information about the preferred protonation state of parietin forming the complex, we tested the protonation states P1 and P2 described in Materials and 
Methods section. We docked parietin structures inside a cavity formed between two steric zippers (model A) and on the surface of one steric zipper (model B); models A and B (Figure 3).

A

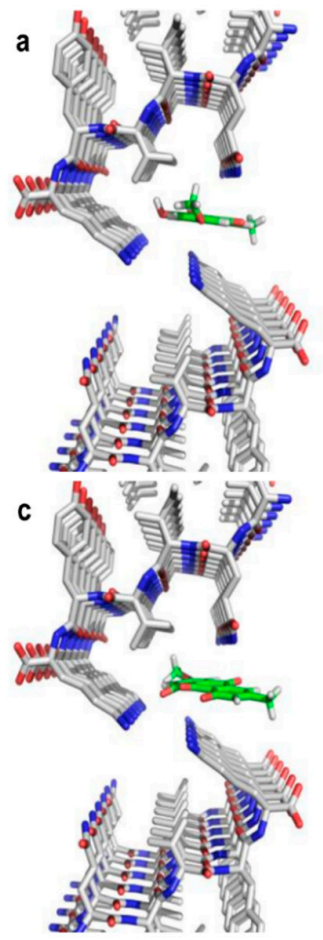

B

a

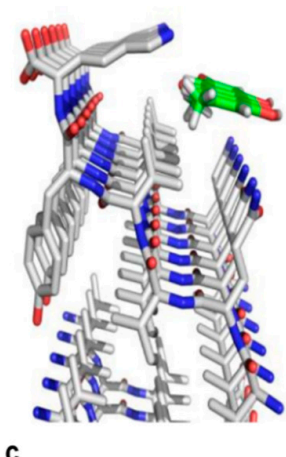$$
\text { c }
$$

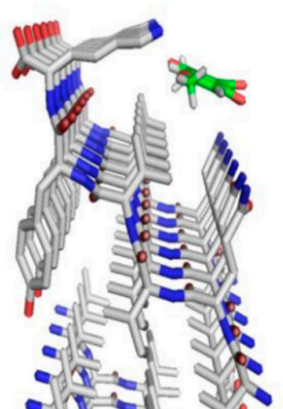

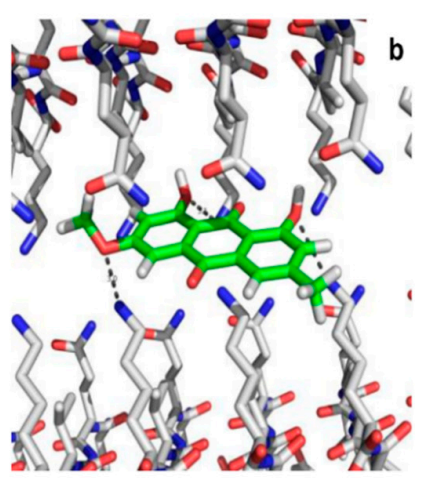
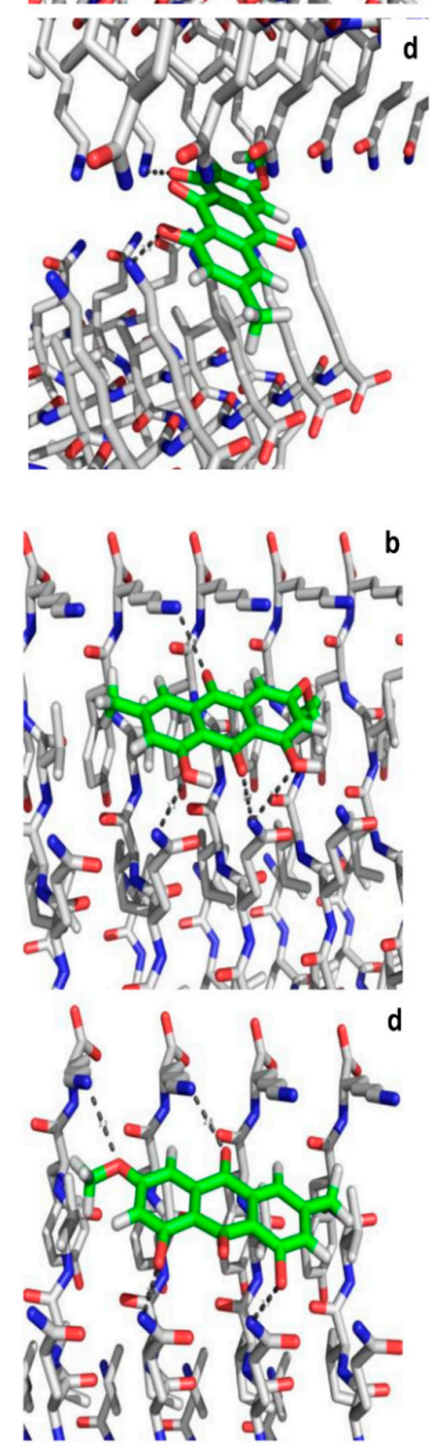

Figure 3. (A) Docking of parietin in protonation state $P 1$ in the interface of two poly-- ${ }^{306}$ VQIVYK ${ }^{311}$ hexapeptide zippers (a,c-left). Hydrogen bounds (HBs) between parietin and lysine residues are indicted as broken lines in the perpendicular view (b,d-right); (B) Docking of parietin in protonation state $\mathrm{P} 2$ in the interface of two poly- ${ }^{306} \mathrm{VQIVYK}^{311}$ hexapeptide zippers (a,c-left). Hydrogen bounds (HBs) between parietin and lysine residues are indicated as broken lines in the perpendicular view (b,d-right). 
Docking results for parietin in protonation states P1 and P2 inside the model $\mathrm{A}$, shown in Figure 3A. The obtained models suggest that parietin could serve as inhibitor of aggregation by binding between steric zippers preventing higher-order $\beta$-sheet interactions as orange-G [37]. The phenolic groups and the oxygen of methoxy substituent form hydrogen bond (HB) interactions with different VQIVYK lysine side chains. At once, the methyl group of the methoxy substituent has hydrophobic interactions with the VYK valine. It is noteworthy that the results are comparable for both protonation states of parietin.

The docking results for parietin in protonation states P1 and P2 inside the model B are shown in Figure 3B. The models obtained show that both protonation states have similar orientations forming HB interactions with lysine and glutamine side chains. Phenolic groups and carbonyl groups at position 9 of the anthracene-9,10-dione scaffold have HB interactions with glutamine side chains, while the oxygen of methoxy substituent and carbonyl at position 10 of the anthracene-9,10-dione scaffold have HB interactions with lysine side chains. At the same time, methyl groups orient near VYK valine forming hydrophobic interactions.

Regarding the HPLC fingerprint of the methanolic extract, 22 compounds were identified for the first time in the methanolic extract of $R$. terebrata with the help of their characteristic UV-Vis spectra and high-resolution mass spectrometry [38,39]. All compounds were detected in negative mode using UHPLC-Q/Orbitrap/ESI/MS/MS (Table 1). Peak 22 was identified as parietin (molecular anion at $m / z$ 283.0601). Peak 21 was identified as usnic acid, which showed a $[\mathrm{M}-\mathrm{H}]^{-}$peak at $m / z 343.0803$. Major diagnostic daughter MS ions of usnic acid were $\left[\mathrm{M}-\mathrm{H}-\mathrm{CH}_{3}\right]^{-}$, $\left[\mathrm{M}-\mathrm{H}-\mathrm{C}_{4} \mathrm{H}_{3} \mathrm{O}_{2}\right]^{-}$ and $\left[\mathrm{M}-\mathrm{H}-\mathrm{C}_{5} \mathrm{H}_{3} \mathrm{O}_{3}\right]^{-}(328.0583,259.0612$ and $231.0663 \mathrm{amu}$, respectively). Peak 20 was identified as lobaric acid (molecular anion at $m / z$ 455.1712). The fragmentation of peak 20 also produced ions at $411.1808\left[\mathrm{M}-\mathrm{H}-\mathrm{CO}_{2}\right]^{-}, 367.1909\left[\mathrm{M}-\mathrm{H}-2 \mathrm{CO}_{2}\right]^{-}, 352.1675\left[\mathrm{M}-\mathrm{H}-2 \mathrm{CO}_{2}-\mathrm{CH}_{3}\right]^{-}$, and $296.1049\left[\mathrm{M}-\mathrm{H}-2 \mathrm{CO}_{2}-\mathrm{C}_{5} \mathrm{H}_{11}\right]^{-}$confirming this depsidone. Peak 19 and 17 had the same $[\mathrm{M}-\mathrm{H}]^{-}$ion at $m / z 375.1070$ with different retention time based on UHPLC at 22.04 and $23.65 \mathrm{~min}$, which were tentatively identified as placodiolic acid or pseudoplacodiolic acid, respectively. Peak 18 with a $[\mathrm{M}-\mathrm{H}]^{-}$ion at $m / z 527.2290$ was identified as arthoniaic acid, and peak 16 as gyrophoric acid, which was identified by spiking experiments with an authentic standard. Peak 15 with a $[\mathrm{M}-\mathrm{H}]^{-}$ion at $m / z 497.1065$ was identified as 3-hydroxyumbilicaric acid. Main daughter ion of peak 15 was at $m / z$ $317.0652\left[\mathrm{M}-\mathrm{H}-\mathrm{C}_{9} \mathrm{H}_{8} \mathrm{O}_{4}\right]^{-}$. Peak 8 could be tentatively identified as 4-O-dimethylbaemycesic acid $\left(m / z\right.$ 359.0756) which produced a MS ${ }^{2}$ ion at $m / z$ 302.0417. Ten tetrahydroxy fatty acids (peak $1-3,5,7$, 9-11 and 13-14) and three pentahydroxy fatty acids (peak 4, 6 and 12) were tentatively identified as the polihydroxy fatty acids reported by Huneck [30].

On the other hand, in recent years, some chemical studies belonging to Ramalina genus have been published and most of the works have been focused on secondary metabolites [40]. Ramalina terebrata Hook and Taylor from the Antarctic is the producer of usnic acid, ramalin, stereocalpin A and usimines A-C [40-43]. Besides, it has been reported from the Ramalina genus isousnic acid, usninic acid, the following depsides sekikaic acid and its 5-OH, 5- $\mathrm{Cl}$ derivatives, $4^{\prime}$-O-methylsekikaic acid, 4'-O-demethylsekikaic acid, 4'-O-methylnorsekikaic, 2'-O-methylsekikaic, homosekikaic acid, 4'-O-methylnorhomosekikaic acid, 4'-O-demethylhomosekikaic acid, atranorin, chloroatranorin, divaricatic acid, ramalinolic acid, obtusatic acid, chlorotumidulin, evernic acid, diffractaic acid, 4'-O-demethylbarbatic acid, ramalinaic acid, cryptochlorophaeic acid and its 4,4'-dimethyl derivative, gyrophoric acid, trivaric acid, perlatolic acid, 4'-O-methylpaludosic acid, boninic acid, stenosporic acid, olivetoric acid, paludosic acid, lecanoric acid, and bourgeanic acid. Also, the following depsidones salazinic acid, norstictic acid, hypoprotocetraric acid, conhypoprotocetraric acid, scopuloric acid, protocetraric acid, connorstictic acid, cryptostictic acid, peristictic acid, variolaric acid, gangaleoidin, physodic acid, and coquimboic acid have been isolated from Ramalina genus. Finally, the fatty acids reported from Ramalina were oleic, palmitic, stearic, linolenic, linoleic, and myristic acids, and the $\gamma$-lactone acids protolichesterinic, D-protolichesterinic, and nephrosterinic [40]. 
Table 1. Identification of metabolites in Antarctic lichen $R$. terebrata by UHPLC-Q/Orbitrap/ESI/MS/MS. * Identified by spiking experiments with an authentic compound; retention time ( $\mathrm{min})$; theoretical and measured mass $(\mathrm{m} / \mathrm{z})$; accuracy $(\mathrm{ppm})$.

\begin{tabular}{|c|c|c|c|c|c|c|c|}
\hline Peak & Tentative Identification & {$[\mathrm{M}-\mathrm{H}]^{-}$} & Retention Time & Theoretical Mass & Measured Mass & Accuracy & MS $^{\text {n }}$ Ions \\
\hline 1 & 9,10,12,13-tetrahydroxyheptadecanoic acid & $\mathrm{C}_{17} \mathrm{H}_{33} \mathrm{O}_{6}$ & 14.53 & 333.2283 & 333.2267 & 4.8 & - \\
\hline 2 & 9,10,12,13-tetrahydroxyoctadecanoic acid & $\mathrm{C}_{18} \mathrm{H}_{35} \mathrm{O}_{6}$ & 15.54 & 347.2439 & 347.2423 & 4.6 & - \\
\hline 3 & 9,10,12,13-tetrahydroxynonadecanoic acid & $\mathrm{C}_{19} \mathrm{H}_{37} \mathrm{O}_{6}$ & 17.45 & 361.2596 & 361.2577 & 5.2 & 343.2472 \\
\hline 4 & 9,10,11,12,13-pentahydroxydocosanoic acid & $\mathrm{C}_{22} \mathrm{H}_{43} \mathrm{O}_{7}$ & 18.54 & 419.3014 & 419.2995 & 4.5 & - \\
\hline 5 & 9,10,12,13-tetrahydroxyeicosanoic acid & $\mathrm{C}_{20} \mathrm{H}_{39} \mathrm{O}_{6}$ & 18.61 & 375.2752 & 375.2736 & 4.2 & $357.2628 ; 187.0962$ \\
\hline 6 & 9,10,11,12,13-pentahydroxytricosanoic acid & $\mathrm{C}_{23} \mathrm{H}_{45} \mathrm{O}_{7}$ & 19.21 & 433.3165 & 433.3150 & 3.5 & - \\
\hline 7 & 9,10,12,13-tetrahydroxyheneicosanoic acid & $\mathrm{C}_{21} \mathrm{H}_{41} \mathrm{O}_{6}$ & 19.29 & 389.2909 & 389.2890 & 4.8 & 371.2782 \\
\hline 8 & 4-O-dimethylbaemycesic acid & $\mathrm{C}_{18} \mathrm{H}_{15} \mathrm{O}_{8}$ & 19.58 & 359.0767 & 359.0756 & 3.0 & - \\
\hline 9 & 9,10,12,13-tetrahydroxyeicosanoic acid & $\mathrm{C}_{20} \mathrm{H}_{39} \mathrm{O}_{6}$ & 19.64 & 375.2747 & 375.2735 & 3.2 & - \\
\hline 10 & 9,10,12,13-tetrahydroxydocosanoic acid & $\mathrm{C}_{22} \mathrm{H}_{43} \mathrm{O}_{6}$ & 19.80 & 403.3065 & 403.3047 & 4.4 & $385.2940 ; 215.1274$ \\
\hline 11 & 9,10,12,13-tetrahydroxyheneicosanoic acid & $\mathrm{C}_{21} \mathrm{H}_{41} \mathrm{O}_{6}$ & 19.95 & 389.2909 & 389.2892 & 4.3 & 371.2782 \\
\hline 12 & 9,10,11,12,13-pentahydroxytetracosanoic acid & $\mathrm{C}_{24} \mathrm{H}_{47} \mathrm{O}_{7}$ & 20.20 & 447.3327 & 447.3306 & 4.7 & - \\
\hline 13 & 9,10,12,13-tetrahydroxydocosanoic acid & $\mathrm{C}_{22} \mathrm{H}_{43} \mathrm{O}_{6}$ & 20.37 & 403.3065 & 403.3043 & 5.4 & 385.2938; 187.0961 \\
\hline 14 & 9,10,12,13-tetrahidroxytricosanoic acid & $\mathrm{C}_{23} \mathrm{H}_{45} \mathrm{O}_{6}$ & 20.79 & 417.3222 & 417.3198 & 5.7 & 399.3094 \\
\hline 15 & 3-hydroxyumbilicaric acid & $\mathrm{C}_{25} \mathrm{H}_{21} \mathrm{O}_{11}$ & 21.25 & 497.1089 & 497.1065 & 4.8 & $317.0652 ; 167.0336$ \\
\hline 16 & Gyrophoric acid* & $\mathrm{C}_{24} \mathrm{H}_{19} \mathrm{O}_{10}$ & 21.27 & 467.0978 & 467.0962 & 3.4 & $317.0647 ; 167.0336 ; 149.0230 ; 123.0438$ \\
\hline 17 & Placodiolic acid or Pseudoplacodiolic acid & $\mathrm{C}_{19} \mathrm{H}_{19} \mathrm{O}_{8}$ & 22.04 & 375.1079 & 375.1070 & 2.4 & $343.0807 ; 259.0598 ; 231.0648$ \\
\hline 18 & Arthoniaic acid & $\mathrm{C}_{29} \mathrm{H}_{36} \mathrm{O}_{9}$ & 22.78 & 527.2281 & 527.2290 & -1.7 & - \\
\hline 19 & Pseudoplacodiolic acid or Placodiolic acid & $\mathrm{C}_{19} \mathrm{H}_{19} \mathrm{O}_{8}$ & 23.65 & 375.1079 & 375.1068 & 2.9 & $343.0805 ; 259.0597 ; 231.0647$ \\
\hline 20 & Lobaric acid * & $\mathrm{C}_{25} \mathrm{H}_{27} \mathrm{O}_{8}$ & 24.82 & 455.1711 & 455.1712 & -0.2 & $411.1808 ; 367.1909 ; 352.1675 ; 296.1049$ \\
\hline 21 & Usnic acid * & $\mathrm{C}_{18} \mathrm{H}_{15} \mathrm{O}_{7}$ & 26.17 & 343.0818 & 343.0803 & 4.3 & $328.0583 ; 259.0612 ; 231.0663$ \\
\hline 22 & Parietin & $\mathrm{C}_{16} \mathrm{H}_{11} \mathrm{O}_{5}$ & 27.21 & 283.0612 & 283.0601 & 3.9 & - \\
\hline
\end{tabular}


Some lichen extracts from the genus Ramalina have displayed a wide range of biological activities such as antimicrobial, antioxidant, antiviral, antitumoral, cytotoxicity, antiinflammatory, and antihelmintic [30,40-46]. An acetone extract of $R$. farinacea demostrated activity against Candida albicans and Candida glabrata at concentrations ranging between 3.3 to $6.6 \mu \mathrm{g} / 25 \mu \mathrm{L}$. Furthemore, a methanolic extract of R. pollinaria showed antibacterial activity and presented MIC values between $5.62-62.5 \mu \mathrm{g} / \mu \mathrm{L}$, while the MIC values for R. polymorpha was $62.5 \mu \mathrm{g} / \mu \mathrm{L}$. Cansaran [44] studied five Ramalina species, and among them the methanolic extract of $R$. fastigiata showed the best inhibition against Bacillus subtilis, Enterococcus faecalis, Escherichia coli and Proteus mirabilis. Methanolic extract from $R$. hossei showed better activity against Gram (+) than against Gram(-) bacteria [45]. The hexanic extract from $R$. roesleri showed a high activity against $S$. aureus and $S$. mutans. In other study, the antibacterial activity of methanolic extract of Antarctic lichen $R$. terebrata displayed considerable antimicrobial activity against Bacillus subtilis (MIC $33.8 \pm 0.15 \mu \mathrm{g} / \mu \mathrm{L}$ ) and S. aureus (MIC $85.7 \pm 6.7 \mu \mathrm{g} / \mathrm{mL}$ ) but no activity against $C$. Albicans, P. aeruginosa, and E. coli, while Paudel et al. [46] reported activity against $S$. aureus. Regarding to antioxidant activity, the methanolic extracts of $R$. pollinaria and R. polymorpha did no show antioxidant properties based on the DPPH method. However, a low inhibition was showed on the oxidation of linoleic acid/ $\beta$-carotene method. The methanolic extract of $R$. hossei and $R$. conduplicans displayed antioxidant potential by the DPPH method and by the reduction of $\mathrm{Fe}^{+3}$ assay. On the other hand, an acetonic extract of $R$. peruviana presented antioxidant activity on the DPPH method (86\%) and $\beta$-carotene assay (57.3\%). A ethanol-water extract (1:1) of $R$. capitata displayed gastroprotective activity $(66 \%)$ at a dose of $200 \mathrm{mg} / \mathrm{kg}$ on the gastric damage model induced by indomethacin, while a methanolic extract of R. cuspidata shows interesting cytotoxic activity particulary in the cell lineages K-562, U251, DU145 and MCF7 [40].

Regarding the lichen-derived substances, usimine $C$ has showed anti-proliferative activity on human dermal fibroblasts [41]. Usnic acid, usimine A-C and ramalin isolated from Antarctic lichen $R$. terebrata, displayed activity against $B$. subtilis but no activity against $S$. aureus, where the values of MIC ranged from 1-26 $\mu \mathrm{g} / \mathrm{mL}$ [40]. Ramalin showed to be a more powerful antioxidant than butylhydroxytoluene (BHT), vitamin E, Trolox and ascorbic acid as well as a very good antiinflammatory agent [43]. Sekikaic acid and homosekikaic acid showed $\mathrm{IC}_{50}$ values of $0.082 \mathrm{mg} / \mathrm{mL}$ and $0.276 \mathrm{mg} / \mathrm{mL}$ at the linoleic acid peroxidation assay, demonstrating that these compounds are promising antioxidants. The antioxidant activity of atranorin, protolichesterinic acid, usnic acid, 2-hydroxy-4-methoxy-6-propylbenzoic acid, homosekikaic acid, sekikaic acid, 2,4-dihydroxy-6-propylbenzoic acid and 2,4-dihydroxy-3,6-dimethylbenzoate isolated from the hexane extract from $R$. roesleri were assessed by the DPPH method. Among the compounds, the best antioxidant activity was exhibited by sekikaic acid, followed by homosekikaic acid. Usnic acid has demostrated to reduce the production of Junin virus in infected Vero cells in a dependent dose manner $\left(\mathrm{EC}_{50} 9.9 \mu \mathrm{M}\right)$, these results indicate that usnic acid present antiviral activity. Also, usnic acid is not genotoxic and cytotoxic towards human lymphocyte A549, promyelocytic leukemia HL-60, and ovarian carcinoma A2780. D-protolichesterinic acid and nephrosterinic acid showed activity against Ehrlich carcinoma. D-protolichesterinic acid and lobaric acid are considered 5- and 12-lipoxygenase inhibitors [40].

\section{Materials and Methods}

\subsection{Collection and Identification of Lichen Species}

Ramalina terebrata was collected in "Peninsula Fildes" Antarctic region, Chile during March, 2014. Lichens were carefully removed from the rocks by abrasion. A voucher specimens were deposited at the Extreme Natural Product laboratory, Universidad de Chile whose reference numbers is RT-010414. R. terebrata $(50 \mathrm{~g})$ were dried, powdered and extracted with methanol $(3 \times 0.5 \mathrm{~L})$ to afford, after evaporation of the solvent under vacuum, $450 \mathrm{mg}$ of a dark gum. 


\subsection{Extraction}

The methanolic extract was subjected to Sephadex LH-20 and eluted with MeOH. Fractions $(10 \mathrm{~mL})$ were monitored by TLC and combined to give two main fractions A-B. Further purification was done for the fractions A and B. Fraction A $(200 \mathrm{mg})$ was chromatographed on silica gel (50 g, 63-200 $\mu \mathrm{m}$ ) using n-hexane/EtOAc mixtures ( $\%$ to $100 \%$ ) giving $30 \mathrm{mg}$ of parietin 1 [30] and $54 \mathrm{mg}$ of usnic acid 2 [30]. Fraction B (110 mg) was chromatographed on silica gel (30 g, 63-200 $\mu \mathrm{m})$ using $\mathrm{DCM} / \mathrm{MeOH}$ mixtures ( $0 \%$ to $100 \%$ ) giving $10 \mathrm{mg}$ of parietin 1, $15 \mathrm{mg}$ of atraric acid 3 [30] and $10 \mathrm{mg}$ of inositol 4 [30].

\subsection{Tau Protein Production}

Tau fragment $4 \mathrm{R}$ (htau $244-372)$ was amplified by using the plasmid for htau40 as a template. The PCR sequence was subcloned into pET-28a vector (Novagen, Madinson, WI, USA) to produce a His-tagged protein. The recombinant fragment 4RMBD was expressed in Escherichia coli strain BL21 (DE3) as described [29]. LB medium containing kanamycin was inoculated with a stationary overnight culture. Bacterial culture was grown at $37^{\circ} \mathrm{C}$ to $\mathrm{OD}_{600}$ of $0.5-0.6$ and protein expression was induced by addition of $1 \mathrm{mM}$ IPTG for $4 \mathrm{~h}$; and cells were pelleted and sonicated. Recombinant tau was purified via a succession of Ni-Sepharose chromatography (equilibrated in $20 \mathrm{mM} \mathrm{NaH}_{2} \mathrm{PO}_{4}$, $500 \mathrm{mM} \mathrm{NaCl}$, and $20 \mathrm{mM}$ imidazole, pH 7.4, elution with buffer $200 \mathrm{mM}$ imidazole) and side exclusion chromatography coupled to HPLC in a Proteema 100 column (PSS, Mainz, Germany) with buffer $50 \mathrm{mM} \mathrm{NaH} \mathrm{PO}_{4}, 300 \mathrm{mM} \mathrm{NaCl}, \mathrm{pH}$ 6.5. The purity of the protein was verified on a Coomassie Brilliant Blue-stained SDS-polyacrylamide gel. The protein was concentrated and stored at $-80^{\circ} \mathrm{C}$ until use. The concentration of purified $4 \mathrm{RMBD}$ was determined using the extinction coefficient at $280 \mathrm{~nm}\left(1520 \mathrm{M}^{-1} \cdot \mathrm{cm}^{-1}\right)$.

\subsection{Thioflavin T Assay}

The ThT fluorescence assay adopted here was modified from the reported by Pickhardt et al. [36]. Briefly, to examine the inhibition of tau aggregation, the total volume of the reaction mixture was $100 \mu \mathrm{L}$, which included $20 \mu \mathrm{M}$ 4RMBD, $5 \mu \mathrm{M}$ heparin in $100 \mathrm{mM}$ sodium acetate, $\mathrm{pH} 7.0$ with parietin at different concentrations. After $20 \mathrm{~h}$ of incubation at $37^{\circ} \mathrm{C}$, addition of $100 \mu \mathrm{L}$ of a $25 \mu \mathrm{M}$ solution of ThT was made and incubation continued for $1 \mathrm{~h}$ at room temperature prior to fluorescence reading. Then, the fluorescence was measured in a Biotek H1 multi-mode reader (Biotek Instruments, Winooski, VT, USA) with an excitation wavelength at $440 \mathrm{~nm}$ and emission wavelength of $485 \mathrm{~nm}$ in a 96-well plate. Each experiment was replicated at least three times and background fluorescence was subtracted.

\subsection{UHPLC-Q/Orbitrap/MS/MS}

\subsubsection{Instrument}

A Thermo Scientific Dionex Ultimate 3000 UHPLC system equipped with a quaternary Series RS pump and a Thermo Scientific Dionex Ultimate 3000 Series TCC-3000RS column compartments with a Thermo Fisher Scientific Ultimate 3000 Series WPS-3000RS autosampler and a rapid separations PDA detector controlled by Chromeleon 7.2 Software (Thermo Fisher Scientific, Bremen, Germany) hyphenated with a Thermo high resolution $Q$ Exactive focus mass spectrometer were used for analysis. The chromatographic system was coupled to the MS with a Heated Electrospray Ionization Source II (HESI II). Nitrogen (purity > 99.999\%) obtained from a Genius NM32LA nitrogen generator (Peak Scientific, Billerica, MA, USA) was employed as both the collision and damping gas. Mass calibration for Orbitrap was performed once a week, in both negative and positive modes, to ensure a working mass accuracy lowers than or equal to $5 \mathrm{ppm}$. Cafeine and $\mathrm{N}$-butylamine (Sigma Aldrich, Saint Louis, MO, USA) were the calibration standards for positive ions and buspirone hydrochloride, sodium dodecyl sulfate, and taurocholic acid sodium salt were used to calibrate the mass spectrometer. These compounds were dissolved in a mixture of acetic acid, acetonitrile, water and 
methanol (Merck Darmstadt, Hesse, Germany) and were infused using a Chemyx Fusion 100 syringe pump. XCalibur 2.3 software and Trace Finder 3.2 (Thermo Fisher Scientific, San Jose, CA, USA) were used for UHPLC control and data processing, respectively. Q Exactive 2.0 SP 2 from Thermo Fisher Scientific was used to control the mass spectrometer.

\subsubsection{LC Parameters}

Liquid chromatography was performed using an UHPLC C18 column (Acclaim, $150 \mathrm{~mm} \times 4.6 \mathrm{~mm}$ ID, $5 \mathrm{~m}$ ) operated at $25{ }^{\circ} \mathrm{C}$. The detection wavelengths were $254,280,320$ and $440 \mathrm{~nm}$, and PDA was recorded from 200 to $800 \mathrm{~nm}$ for peak characterization. Mobile phases were $1 \%$ formic aqueous solution (A) and acetonitrile (B). The gradient program (time ( $\mathrm{min}), \% \mathrm{~B}$ ) was: $(0.00,5) ;(5.00,5) ;(10.00,30) ;(15.00,30) ;(20.00,70) ;(25.00,70) ;(35.00,5)$ and 12 min for column equilibration before each injection. The flow rate was $1.00 \mathrm{~mL} \cdot \mathrm{min}^{-1}$, and the injection volume was $10 \mu \mathrm{L}$. Standards and lichen extracts dissolved in methanol were kept at $10{ }^{\circ} \mathrm{C}$ during storage in the autosampler.

\subsubsection{MS Parameters}

The HESI parameters were optimized as follows: sheath gas flow rate 75 units; aux. gas unit flow rate 20; capillary temperature $400{ }^{\circ} \mathrm{C}$; aux gas heater temperature $500{ }^{\circ} \mathrm{C}$; spray voltage $2500 \mathrm{~V}$ (for $\mathrm{ESI}^{-}$); and S lens RF level 30. Full scan data in both positive and negative was acquired at a resolving power of 70,000 FWHM (full width half maximum) at $m / z 200$. For the compounds of interest, a scan range of $m / z 100-1000$ was chosen; the automatic gain control (AGC) was set at $3 \times 10^{6}$ and the injection time was set to $200 \mathrm{~ms}$. Scan-rate was set at $2 \mathrm{scans} \cdot \mathrm{s}^{-1}$. External calibration was performed using a calibration solution in positive and negative modes before each sample series. In addition to the full scan acquisition method, for confirmations purposes, a targeted MS/MS analysis was performed using the mass inclusion list and expected retention times of the target analytes, with a $30 \mathrm{~s}$ time window, with the Orbitrap spectrometer operating both in positive and negative mode at $17,500 \mathrm{FWHM}(\mathrm{m} / \mathrm{z} 200)$. The AGC target was set to $2 \times 10^{5}$, with the maximum injection time of $20 \mathrm{~ms}$. The precursor ions are filtered by the quadrupole which operates at an isolation window of $m / z$ 2. The fore vacuum, high vacuum and ultrahigh vacuum were maintained at approximately 2 mbar, from 105 and below 1010 mbar, respectively. Collision energy (HCD cell) was operated at $30 \mathrm{kV}$. Detection was based on calculated exact mass and on retention time of target compounds, as shown in Table 1 . The mass tolerance window was set to $5 \mathrm{ppm}$ for the two analysis modes.

\subsection{Molecular Modeling}

The current structural information about tau protein is very limited; however, our results suggest that parietin could interact with tau fibril-forming motifs VQIINK $\left(\mathrm{PHF}^{*}\right)$, particularly with lysine residues. The coordinates of the hexapeptide VQIVYK were extracted from the X-ray crystal structure of tau VQIVYK segment complexed with orange-G (Protein Data Bank code 3OVL) $[47,48]$. The fiber structure was prepared using the VQIVYK coordinates. Zinc atoms were removed since zinc solution was not used in our study. We prepared two fiber structure models A and B: A contains 24 units of hexapeptide and B contains 12 units of the hexapeptide. In model A, each member of a pair of VQIVYK $\beta$-sheets is shifted relative to the other, without the dry interface in the typical steric zipper structure, forming a cylindrical cavity $[47,48]$; docking was executed inside the cavity. The model B just contains the half of peptides of model A, and B does not contain a cavity; therefore, the docking was executed at surface. Using models A and B, we evaluated the interactions between the parietin and the VQIVYK fiber structure using these models considering the presence and absence of a cavity.

For docking, we considered two protonation states of parietin: P1 with neutral phenolic groups, and P2 with deprotonated phenolic groups. These two extreme cases allow studying the effect of the protonation state of molecular interactions with hexapeptide VQIVYK. Both models of parietin (P1 and P2) were sketched using Maestro's molecular editor. 
Docking was performed using Glide method [47,48]. A grid box of $15 \AA$ × $10 \AA$ × $10 \AA$ covered the whole cavity in model A, and whole surface in model B. Docking parameters were used as previously reported, a Glide extra-precision (XP) modes were explored during search. Docking hierarchy begins with systematic conformational expansion of ligand followed by placement on receptor site. Then, minimization of the ligand in the receptor field was carried out using the OPLS-AA [49] force field with a distance-dependent dielectric of 2.0. Afterwards, the lowest energy poses were subjected to a Monte Carlo procedure that samples the nearby torsional minima. The best pose for a given ligand was determined by the Emodel score, while different compounds were ranked using GlideScore [50]. Docking poses were analyzed by examining their relative total energy score. The most energetically favorable conformations were selected as best poses.

\subsection{Statistical Analysis}

Results of statistical analysis were expressed as the mean \pm SEM. In all experiments, statistical differences between treatments and their respective control were determined by Paired $t$-test. Significance level was set at $p<0.05$. All statistical analyses were developed using GraphPad Prism 6 software (H. Motulsky, San Diego, CA, USA).

\section{Conclusions}

Finally, our results demonstrate that parietin has a moderate activity against the aggregation process of tau protein, while the methanolic extract of Ramalina terebrata had also activity that could be attributed to sinergistic effects of the compounds detected in the extract. On the other hand, docking experiments suggest that parietin is bound to fiber-forming segment VQIVYK of tau mediated mainly by HBs interactions with the lysine residues. Based on UHPLC-Q/Orbitrap/ESI/MS/MS, 22 compounds were identified in the methanolic extract of the Antarctic lichen Ramalina terebrata. Finally, in-depth analysis of the chemical composition of $R$. terebrata could guide further research into its medicinal properties and potential uses.

Supplementary Materials: Supplementary materials can be found at www.mdpi.com/1422-0067/17/8/1303/s1.

Acknowledgments: This work was supported by grants from the INACH RT 13-13 to Alberto Cornejo and Carlos Areche, and INACH MT 03-14 to Francisco Salgado. Julio Caballero acknowledge funds of FONDECYT Regular \# 1130141. Mario Simirgiotis acknowledge Fondequip (grant EQM140002) for the funding to purchase the UHPLC/Orbitrap/ESI/MS/MS equipment.

Author Contributions: Carlos Areche and Alberto Cornejo conceived and designed the experiments; Francisco Salgado performed the experiments; Julio Caballero performed the molecular modeling; Reinaldo Vargas identified the specimens; Mario Simirgiotis analyzed the data of HPLC/MS; Carlos Areche and Alberto Cornejo wrote the paper. All authors read and approved the final manuscript.

Conflicts of Interest: The authors declare no conflict of interest.

\section{References}

1. Shukla, V.; Joshi, G.; Rawat, M.S.M. Lichens as a potential natural source of bioactive compounds: A review. Phytochem. Rev. 2010, 9, 303-314. [CrossRef]

2. Molnar, K.; Farkas, E. Current results on biological activities of lichen secondary metabolites: A review. Z. Naturforsch. C 2010, 65, 157-173. [CrossRef]

3. Basile, A.; Rigano, D.; Loppi, S.; di Santi, A.; Nebbioso, A.; Sorbo, S.; Conte, B.; Paoli, L.; de Ruberto, F.; Molinari, A.M.; et al. Antiproliferative, antibacterial and antifungal activity of the lichen Xanthoria parietina and its secondary metabolite parietin. Int. J. Mol. Sci. 2015, 16, 7861-7875. [CrossRef] [PubMed]

4. Gauslaa, Y.; Ustvedt, E.M. Is parietin a UV-B or a blue light screening pigment in lichen Xanthoria parietina. Photochem. Photobiol. Sci. 2003, 2, 424-432. [CrossRef]

5. Boustie, J.; Grube, M. Lichens-A promising source of bioactive secondary metabolites. Plant Genet. Resour. 2005, 3, 273-287. [CrossRef] 
6. Muller, K. Pharmaceutically relevant metabolites from lichens. Appl. Microbiol. Biotechnol. 2001, 56, 9-16. [CrossRef] [PubMed]

7. Stocker-Worgotter, E. Metabolic diversity of lichen-forming ascomycetous fungi: Culturing, polyketide and shikimate metabolite production, and PKS genes. Nat. Prod. Rep. 2008, 25, 188-200. [CrossRef] [PubMed]

8. Gotz, J.; Ittner, A.; Ittner, L.M. Tau-targeted treatment strategies in Alzheimer's disease. Br. J. Pharmacol. 2012, 165, 1246-1259. [CrossRef] [PubMed]

9. Grundke-Iqbal, I.; Iqbal, K.; Tung, Y.C.; Quinian, M.; Wisniewski, H.M.; Binder, L.I. Abnormal phosphorylation of the microtubule-associated protein tau in Alzheimer cytoskeletal pathology. Proc. Natl. Acad. Sci. USA 1986, 83, 4913-4917. [CrossRef]

10. Von Bergen, M.; Friedhoff, P.; Biernat, J.; Heberle, J.; Mandelkow, E.M.; Mandelkow, E. Assembly of $\tau$ protein into Alzheimer paired helical filaments depends on a local sequence motif $\left({ }^{306} \mathrm{VQIVYK}^{311}\right)$ forming $\beta$ structure. Proc. Natl. Acad. Sci. USA 2000, 97, 5129-5134. [CrossRef] [PubMed]

11. Yu, X.; Luo, Y.; Dinkel, P.; Zheng, J.; Wei, G.; Margittai, M.; Nussinov, R.; Ma, B. Cross-seeding and conformational selection between three- and four-repeat human tau proteins. J. Biol. Chem. 2012, 287, 14950-14959. [CrossRef] [PubMed]

12. Mukrasch, M.D.; Biernat, J.; von Bergen, M.; Griesinger, C.; Mandelkow, E.; Zweckstetter, M. Sites of tau important for aggregation populate $\beta$-structure and bind to microtubules and polyanions. J. Biol. Chem. 2005, 280, 24978-24986. [CrossRef] [PubMed]

13. Zhu, H.L.; Fernandez, C.; Fan, J.B.; Shewmaker, F.; Chen, J.; Minton, A.P.; Liang, Y. Quantitative characterization of heparin binding to tau protein implication for inducer-mediated tau filament formation. J. Biol. Chem. 2010, 285, 3592-3599. [CrossRef] [PubMed]

14. Nelson, R.; Eisenberg, D. Recent atomic models of amyloid fibril structure. Curr. Opin. Struct. Biol. 2006, 16, 260-265. [CrossRef] [PubMed]

15. Kirschner, D.A.; Abraham, C.; Selkoe, D.J. X-ray diffraction from intraneuronal paired helical filaments and extraneuronal amyloid fibers in Alzheimer disease indicates cross- $\beta$ conformation. Proc. Natl. Acad. Sci. USA 1986, 83, 503-507. [CrossRef] [PubMed]

16. Nelson, R.; Sawaya, M.R.; Balbirnie, M.; Madsen, A.; Riekel, C.; Grothe, R.; Eisenberg, D. Structure of the cross- $\beta$ spine of amyloid-like fibrils. Nature 2005, 435, 773-778. [CrossRef] [PubMed]

17. Martinez-Dominguez, G.; Romero-González, R.; Garrido Frenich, A. Multi-class methodology to determine pesticides and mycotoxins in green tea and royal jelly supplements by liquid chromatography coupled to Orbitrap high resolution mass spectrometry. Food Chem. 2016, 197, 907-915. [CrossRef] [PubMed]

18. Chitescu, C.L.; Kaklamanos, G.; Nicolau, A.I.; Stolker, A.A.M. High sensitive multiresidue analysis of pharmaceuticals and antifungals in surface water using U-HPLC-Q-Exactive Orbitrap HRMS. Application to the Danube river basin on the Romanian territory. Sci. Total Environ. 2015, 532, 501-511. [CrossRef] [PubMed]

19. Simirgiotis, M.J.; Borquez, J.; Neves-Vieira, M.; Brito, I.; Alfaro-Lira, S.; Winterhalter, P.; Echiburu-Chau, C.; Jerz, G.; Cardenas, A. Fast isolation of cytotoxic compounds from the native Chilean species Gypothamnium pinifolium Phil. collected in the Atacama Desert, northern Chile. Ind. Crops Prod. 2015, 76, 69-76. [CrossRef]

20. Simirgiotis, M.J.; Quispe, C.; Areche, C.; Sepulveda, B. Phenolic compounds in Chilean Mistletoe (Quintral, Tristerix tetrandus) analyzed by UHPLC-Q/Orbitrap/MS/MS and its antioxidant properties. Molecules 2016, 21, 245-260. [CrossRef] [PubMed]

21. Simirgiotis, M.J.; Quispe, C.; Borquez, J.; Areche, C.; Sepulveda, B. Fast detection of phenolic compounds in extracts of Easter Pears (Pyrus communis) from the Atacama Desert by ultrahigh-performance liquid chromatography and mass spectrometry (UHPLC-Q/Orbitrap/MS/MS). Molecules 2016, 21, 92-106. [CrossRef] [PubMed]

22. Ramirez, D.; Caballero, J. Is it reliable to use common molecular docking methods for comparing the binding affinities of enantiomers pairs for their protein target? Int. J. Mol. Sci. 2016, 17, 525-540. [CrossRef] [PubMed]

23. Kaur, J.; Sundar, S.; Singh, N. Molecular docking, structure-activity relationship and biological evaluation of the anticancer drug monastrol as a pteridine reductase inhibitor in a clinical isolate of Leishmania donovani. J. Antimicrob. Chemother. 2010, 65, 1742-1748. [CrossRef] [PubMed] 
24. Han, X.; Fan, J.; Lu, H.; Wan, C.; Li, X.; Li, H.; Yang, D.; Zhang, Y.; Xiao, Y.; Qin, Z. Synthesis, resolution and biological evaluation of cyclopropyl analogs of abscisic acid. Bioorg. Med. Chem. 2015, 23, 6210-6217. [CrossRef] [PubMed]

25. Grulich, M.; Brezovsky, J.; Stepanek, V.; Palyzova, A.; Kyslikova, E.; Kyslik, P. Resolution of $\alpha / \beta$-amino acids by enantioselective penicillin G acylase from Achromobacter sp. J. Mol. Catal. B Enzym. 2015, 122, 240-247. [CrossRef]

26. Ibrahim, M.A.; Abou-Seri, S.M.; Hanna, M.M.; Abdalla, M.M.; El Sayed, N.A. Design, synthesis and biological evaluation of novel condensed pyrrolo[1,2-c] pyrimidines featuring morpholine moiety as PI3K $\alpha$ inhibitors. Eur. J. Med. Chem. 2015, 99, 1-13. [CrossRef] [PubMed]

27. Uysal, A.; Zengin, G.; Mollica, A.; Gunes, E.; Locatelli, M.; Yilmaz, T.; Aktumsek, A. Chemical and biological insights on Cotoneaster integerrimus: A new (-)-epicatechin source of food and medicinal applications. Phytomedicine 2016, 23, 979-988. [CrossRef] [PubMed]

28. Mocan, A.; Zengin, G.; Uysal, A.; Gunes, E.; Mollica, A.; Degirmenci, N.S.; Alpsoy, L.; Aktumsek, A. Biological and chemical insights of Morina persica L.: A source of bioactive compounds with multifunctional properties. J. Funct. Foods 2016, 25, 94-109. [CrossRef]

29. Cornejo, A.; Jimenez, J.M.; Caballero, L.; Melo, F.; Maccioni, R.B. Fulvic acid inhibits aggregation and promotes disassembly of tau fibrils associated with Alzheimer's disease. J. Alzheimers. Dis. 2011, 27, 143-153. [PubMed]

30. Huneck, S.; Yoshimura, I. Data of lichen substances. In Identification of Lichen Substances; Springer Verlag: Berlin, Germany, 1996; Volume 3, pp. 125-446.

31. Naiki, H.; Higuchi, K.; Hosokawa, M.; Takeda, T. Fluorometric determination of amyloid fibrils in vitro using the fluorescent dye, thioflavine T. Anal. Biochem. 1989, 177, 244-249. [CrossRef]

32. Levine, $\mathrm{H}$. Thioflavine $\mathrm{T}$ interaction with synthetic Alzheimer's disease $\beta$-amyloid peptides: Detection of amyloid aggregation in solution. Protein Sci. 1993, 2, 404-410. [CrossRef] [PubMed]

33. Taniguchi, S.; Suzuki, N.; Masuda, M.; Hisanaga, S.; Iwatsubo, T.; Goedert, M.; Hasegawa, M. Inhibition of heparin-induced tau filament formation by phenothiazines, polyphenols, and porphyrins. J. Biol. Chem. 2005, 280, 7614-7623. [CrossRef] [PubMed]

34. Porat, Y.; Abramowitz, A.; Gazit, E. Inhibition of amyloid fibril formation by polyphenols: Structural similarity and aromatic interactions as a common inhibition mechanism. Chem. Biol. Drug Des. 2006, 67, 27-37. [CrossRef] [PubMed]

35. Crowe, A.; Ballatore, C.; Hyde, E.; Trojanowski, J.Q.; Lee, V.M. High throughput screening for small molecule inhibitors of heparin-induced tau fibril formation. Biochem. Biophys. Res. Commun. 2007, 358, 1-6. [CrossRef] [PubMed]

36. Pickhardt, M.; Gazova, Z.; von Bergen, M.; Khlistunova, I.; Wang, Y.; Hascher, A.; Mandelkow, E.M.; Biernat, J.; Mandelkow, E. Anthraquinones inhibit tau aggregation and dissolve Alzheimer's paired helical filaments in vitro and in cells. J. Biol. Chem. 2005, 280, 3628-3635. [CrossRef] [PubMed]

37. Landau, M.; Sawaya, M.R.; Faull, K.F.; Laganowsky, A.; Jiang, L.; Sievers, S.A.; Liu, J.; Barrio, J.R.; Eisenberg, D. Towards a pharmacophore for amyloid. PLoS Biol. 2011, 9, e1001080. [CrossRef] [PubMed]

38. Le Pogam, P.; Schinkovitz, A.; Legouin, B.; Le lamer, A.; Boustie, J.; Richomme, P. Matrix-free UV-laser desorption ionization mass spectrometry as a versatile approach for accelerating dereplication studies on lichens. Anal. Chem. 2015, 87, 10421-10428. [CrossRef] [PubMed]

39. Musharraf, S.G.; Kanwal, N.; Thadhani, V.M.; Choudhary, M.I. Rapid identification of lichen compounds based on the structure-fragmentation relationship using ESI-MS/MS analysis. Anal. Methods 2015, 7, 6066-6076. [CrossRef]

40. Moreira, A.S.N.; Braz-Filho, R.; Mussi-Dias, V.; Vieira, I.J.C. Chemistry and biological activity of Ramalina lichenized fungi. Molecules 2015, 20, 8952-8987. [CrossRef] [PubMed]

41. Lee, S.G.; Koh, H.Y.; Oh, H.; Han, S.J.; Kim, I.C.; Lee, H.K.; Yim, J.H. Human dermal fibroblast proliferation activity of usimine-C from Antarctic lichen Ramalina terebrata. Biotechnol. Lett. 2010, 32, 471-475. [CrossRef] [PubMed]

42. Byeon, H.E.; Park, B.K.; Yim, J.H.; Lee, H.K.; Moon, E.Y.; Rhee, D.K.; Pyo, S. Stereocalpin A inhibits the expression of adhesion molecules in activated vascular smooth muscle cells. Int. Immunopharmacol. 2012, 12, 315-325. [CrossRef] [PubMed] 
43. Paudel, B.; Bhattarai, H.D.; Koh, H.Y.; Lee, S.G.; Han, S.J.; Lee, H.K.; Oh, H.; Shin, H.W.; Yim, J.H. Ramalin, a novel nontoxic antioxidant compound from the Antarctic lichen Ramalina terebrata. Phytomedicine 2011, 18, 1285-1290. [CrossRef] [PubMed]

44. Cansaran, D.; Atakol, O.; Halici, M.G.; Aksoy, A. HPLC analysis of usnic acid in some Ramalina species from Anatolia and investigation of their antimicrobial activities. Pharm. Biol. 2007, 45, 77-81. [CrossRef]

45. Vinayaka, K.S.; Kekuda, T.R.P.; Swathi, D.; Kumar, S.V. Studies on chemical composition and in vitro antibacterial activity od solvent extracts of the lichen Ramalina hossei. BioTechnol. Indian J. 2009, 3, 309-311.

46. Paudel, B.; Bhattarai, H.D.; Lee, H.K.; Oh, H.; Shin, H.W.; Han, J.; Yim, J.H. Antibacterial activities of ramalin, usnic acid, and its three derivatives isolates from the Antarctic lichen Ramalina terebrata. Z. Naturforschung. C 2010, 65, 34-38.

47. Alzate-Morales, J.H.; Vergara-Jaque, A.; Caballero, J. Computational study on the interaction of N1 substituted pyrazole derivatives with B-Raf kinase: An unusual water wire hydrogen-bond network and novel interactions at the entrance of the active site. J. Chem. Inf. Model. 2010, 50, 1101-1112. [CrossRef] [PubMed]

48. Friesner, R.A.; Banks, J.L.; Murphy, R.B.; Halgren, T.A.; Klicic, J.J.; Mainz, D.T.; Repasky, M.P.; knoll, E.H.; Shelley, M.; Perry, J.K.; et al. Glide: A new approach for rapid, accurate docking and scoring 1 . Method and assessment of docking accuracy. J. Med. Chem. 2004, 47, 1739-1749. [CrossRef] [PubMed]

49. Jorgensen, W.L.; Maxwell, D.S.; Tirado-Rives, J. Development and testing of the OPLS all-atom force field on conformational energetics and properties of organic liquids. J. Am. Chem. Soc. 1996, 118, 11225-11236. [CrossRef]

50. Eldridge, M.D.; Murray, C.W.; Auton, T.R.; Paolini, G.V.; Mee, R.P. Empirical scoring functions: The development of a fast empirical scoring function to estimate the binding affinity of ligands in receptor complexes. J. Comput. Aided Mol. Des. 1997, 11, 425-445. [CrossRef] [PubMed]

(c) 2016 by the authors; licensee MDPI, Basel, Switzerland. This article is an open access article distributed under the terms and conditions of the Creative Commons Attribution (CC-BY) license (http://creativecommons.org/licenses/by/4.0/). 